JANÉ, Òscar i Solé, Queralt (eds.) (2011)

Observar les fronteres, veure el món

València: Afers, $350 \mathrm{p}$.

ISBN: 978-84-92542-50-5

El llibre que ressenyem recull els treballs presentats en una trobada d'investigadors per reflexionar sobre fronteres i és el segon número d'una col-lecció coeditada pel grup Mirmanda ${ }^{1}$ i per l'editorial Afers. El primer volum d'aquesta (Jané i Forcada, 2011) presentava la mirada del grup amb la voluntat de transgredir, amb el pensament, la petjada que han deixat les fronteres polítiques. El llibre és un bon preludi del que ressenyem, amb l'aproximació a sofriments per l'exili, a pràctiques de resiliència enfront de la dominació i la frontera, a la memòria de l'articulació transfronterera inscrita en la literatura, al reflex lingüístic de trànsits i contactes constants i perllongats, al pas d'una llengua a una altra, al punt de connexió entre humanitat i natura, al valor de les fronteres territorials i paisatgístiques, a les esmunyedisses fronteres marítimes, als viaranys de la filosofia catalana de mitjan segle XIX i a la retirada com a oportunitat per a l'aflorament de la complexa mirada afronterera.

El volum que ens ocupa té quatre seccions. La primera («Fronteres al segle XXI») l'obre un text de Perrin sobre l'acció cultural euroregional. La cultura esdevé un eix de cooperació presumptament capaç de generar sentiment de pertinença, però en un procés de cerca de legitimació institucional que no només no depassa les fronteres, sinó que les evoca. En els dos casos analitzats (l'Euroregió MigdiaPirineus i la Gran Regió, que agrupa diversos Länder alemanys, Luxemburg i tres entitats federades belgues), sembla que diverses accions en el camp cultural reforcin la identitat transfronterera, perquè potencien relacions institucionals $\mathrm{i}$

entre entitats de la societat civil en un marc transfronterer. Amb tot, esdevé una producció elitista i llunyana a la realitat dels llocs.

En un segon text, Gardaix aborda les fronteres marítimes. Si tota frontera convida al creuament i recorda, amb l'acte de delimitació, la impossibilitat mateixa de la impermeabilitat, això és especialment clar en les fronteres marítimes. Amb tot, la importància del mar per al transport en context de globalització redimensiona els acords de delimitació. Mentre les fronteres són rígides a l'ús dels recursos marítims, es fan poroses per facilitar els intercanvis internacionals en una mena de cooperació mundial reticular. Les fronteres marítimes reflecteixen el repte de la combinació entre les porositats que deriven de la globalització i l'exigència social d'una governabilitat que comporti la regulació de fronteres.

Un tercer treball — de Ferrer-Gallardó- tracta el cas de Ceuta-Marroc. S'hi combinen quatre discontinuïtats (políticoterritorial, cultural, de comerç formal i de la migració) i quatre continuïtats (laboral, social, econòmica i de cooperació). Les tensions entre continuïtats i discontinuïtats es conjuguen amb el desplaçament del centre de poder des de Ceuta fins al nord del Marroc per les relacions entre estats i per la dinamització econòmica que comporten projectes urbanístics i turístics en aquella zona.

Aquesta primera part la tanquen dos textos més. Al primer, Gallardo enfoca com les representacions de fronteres en didàctica mostren la reproducció del concepte geopolític de frontera territorial, tot i els contrastos amb la natura o

1. Ciutat imaginària ubicada al Rosselló que apareix al poema Canigó, de Jacint Verdaguer. 
l'existència de fronteres diferents de les territorials o de dinàmiques que les superen. El segon text - de Sancho- presenta la Terreta (Ribagorça) des de l'anàlisi cartogràfica, en una comparació d'usos del territori en diferents etapes recents que evidencien les dificultats que suposen la divisió administrativa i la fragmentació sectorial de les polítiques per recuperar alguns elements del paisatge i usos dels recursos.

La segona part del llibre («Espais de frontera») l'obren Pallarès i Tulla tot tractant Andorra i la Seu d'Urgell com a ciutats bessones que combinen economies aparentment independents amb una realitat geogràfica i cultural comuna. El model comporta beneficis financers i demogràfics per a totes dues parts, però presenta reptes en cotitzacions i prestacions per als commuters, participació política, medi ambient i circulació. El rol de la frontera com a motor de desenvolupament regional i vector de canvis històrics — present en aquest cas - es troba al text d'Hidalgo i Cubas sobre Arribes del Duero. A aquests dos treballs, s'hi sumen els de Cebollada i Espluga i De Giralt. El primer s'aproxima a la Franja aragonesa, tot criticant un cert «nacionalisme metodològic» que impedeix veure trajectòries transfrontereres i que se suma a una acció institucional i política excessivament confinada en territoris adscrits a una administració determinada. Giralt, d'altra banda, tracta la plasmació d'alguns resultats del contacte de llengües en el cas de la Llitera.

A la tercera part del llibre ("Quan els límits han d'esdevenir frontera»), els textos de Molí i Assénat i Pérez són els que tracten períodes més antics. El primer analitza les relacions entre Barcelona i Perpinyà a través dels obradors de Ripoll i de l'escultor Domènec Casamira (15921659) i el segon presenta com una ciutat pot ser central, des de l'antiguitat, per establir una frontera. Més ençà en el temps, el text d'Issartel presenta la gènesi teologicopolítica de la noció moderna de frontera, des de les bases religioses fins a la secularització posterior amb l'associació a la "civilització» o al dret natural dels pobles. La secularització de la política es troba també al text de Laurenti sobre la vall de Chisone (als Alps occidentals), que era frontera —al segle XVI- entre el regne de França i el ducat de Savoia. Allà, una divisió religiosa —entre catòlics i valdesos - configurava una frontera cultural amb derivacions polítiques, socials i econòmiques. La secularització posterior de la política sembla que superi el rerefons religiós, per bé que seria interessant conèixer si queda algun vestigi de tot plegat a la memòria i a la reproducció familiar i com es va viure localment la transició al context secularitzat.

El text de Stopani sobre el Ducat de Toscana als segles XVII-XVIII mostra la traducció del límit en frontera per la via de la transmissió intergeneracional de la delimitació a través d'inspeccions a fites que s'aixequen per intervenció d'una autoritat pública, a les quals sovint es feia referència com a resultat d'un consens tàcit o un costum preexistent. Al segle XVI, les fites eren no només pedres, sinó també roques naturals, arbres, parets de penya-segats, edificis, pous o fonts que permetien establir la línia fronterera $\mathrm{i}$ fer-ho, a més, des del llenguatge ordinari. Malgrat tot, al segle XVII, les delimitacions eren revisades constantment i la figura del jutge va guanyar terreny per establir una delimitació precisa. Un segle més tard, s'havia estès de forma considerable l'ús de fites artificials que s'acabava complementant amb l'extensió de l'ús de mapes als textos dels tractats de delimitació. Els sabers especialitzats van anar guanyant els vernaculars en la producció de la frontera. Com mostra el treball de Díaz Matarranz i Díez Torre, l'imperialisme decimonònic exportà aquella noció de les fronteres a països com ara Guinea Equatorial.

La part que tanca el llibre ("Cicatrius de les fronteres») presenta l'ambivalència 
de les fronteres en la història contemporània. Berjoan evidencia (a partir del cas de la frontera dels Pirineus a la premsa rossellonesa del segle XIX) les dificultats dels estats a l'hora de fer respectar llur autoritat en l'àmbit local. Al mateix temps, però, la frontera diferencia consciències locals forjades a partir d'experiències polítiques de vicissituds governamentals i, sobretot, de conflictes bèl.lics. D'altra banda, Balent mostra —amb el cas de Josep Mas Tió (1897-1946) — com el fet de compartir llengua i ideals facilita aglutinar una xarxa transfronterera. Iglesias torna al tema de la llengua per mostrar el seu paper per als refugiats de 1939 com a ferramenta de cohesió, espai d'afirmació individual i representació col-lectiva, forma de resistència i motiu d'esperança en context d'exili.

Als dos darrers treballs del llibre, Comàs i Morales s'endinsen en sengles exemples de literatura per explorar processos de construcció, com són —d'una banda- els de la delimitació de fronteres al si dels textos de la poesia preliminar als impresos perpinyanencs de segle XVII i - d'una altra - el paper de la literatura de frontera en la construcció dels estats nació del Con Sud; terra buida i sense propietari, espai de projecció sociopolítica i de construcció nacional al marge de les veus indígenes $\mathrm{i}$, sovint, de les femenines. Els relats estableixen continuïtats territorials on no n'hi havia. Els autors esdevenen una elit que troba espai polític i intel-lectual en el projecte de construcció nacional. La literatura de frontera esdevé eina de construcció d'una nació imaginària amb projecció real.

Vista globalment, l'obra parla de fronteres, encara que, sovint, siguin zones de frontera, amb mirades que caldria creuar, pel que fa a metodologia, temporalitat i combinació d'un enfocament micro i macro. En qualsevol cas, el llibre convida a comprendre les fronteres com a talaia d'observació. Pot ser un bon impuls per promoure espais de creuament disciplinari, comparatiu i sistemàtic per a una comprensió holística de les zones de frontera i de les manifestacions d'afrontera.

\section{Referència bibliogràfica}

JANÉ, Òscar i FORCADA, Ėric (eds.) (2011). L'afrontera: De la dominació a l'art de transgredir. València: Afers, $221 \mathrm{p}$.

Albert Moncusi Ferré Universitat de València Departament de Sociologia i Antropologia Social moncusi@uv.es

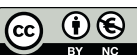

HAYES, Graeme y Karamichas, John (eds.) (2011)

Olympic Games, Mega-Events and Civil Societies:

Globalization, Environment, Resistance

Houndmills: Palgrave Macmillan, 292 p.

ISBN: 978-0-230-24417-7

La ceremonia de inauguración de los Juegos Olímpicos de Londres 2012 fue seguida por más de 900 millones de personas a lo largo y ancho del planeta, y contó con la participación de más de 10.000 atletas de 204 países que compitieron durante
17 días en 35 disciplinas deportivas. De todos modos, tal y como nos recuerdan los autores de Olympic Games, Mega Events and Civil Societies, los megaeventos deportivos y su estudio no pueden reducirse al mundo del deporte ni considerarse 